\title{
Silício alterando compostos derivados da pirólise de bainhas foliares de plantas de arroz infectadas por Rhizoctonia solani
}

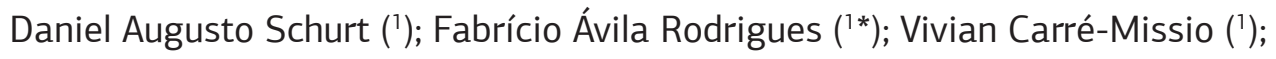 \\ Nilda Fátima Ferreira Soares $\left({ }^{2}\right)$ \\ (') Universidade Federal de Viçosa (UFV), Departamento de Fitopatologia, Laboratório da Interação Planta-Patógeno, Av. P. H. Rolfs \\ s/n, 36570-000 Viçosa (MG), Brasil. \\ (2) UFV, Departamento de Tecnologia de Alimentos, 36570-000 Viçosa (MG), Brasil. \\ (*) Autor correspondente: fabricio@ufv.br
}

Recebido: 16/jan./2013; Aceito: 27/mar./2013

\begin{abstract}
Resumo
Este trabalho teve como objetivo elucidar, por meio da pirólise analítica acoplada à cromatografia gasosa e espectrometria de massa, alterações na composição química da lignina nas bainhas de plantas de arroz das cultivares BR-Irga 409 e Labelle supridas ou não com silício (Si) e infectadas por Rhizoctonia solani. A concentração de Si nas bainhas das plantas supridas com esse elemento foi significativamente maior (2,7 dag $\mathrm{kg}^{-1}$ ) em comparação com as plantas não supridas $\left(0,45\right.$ dag $\left.\mathrm{kg}^{-1}\right)$. Na presença de Si, a área abaixo da curva do progresso da queima das bainhas foi significativamente reduzida em 19 e 25\%, respectivamente, para as plantas das cultivares BR-Irga-409 e Labelle em relação à ausência desse elemento na solução nutritiva. Com base nos espectros de massas obtidos, foram identificados 33 compostos, dos quais 10 foram produtos da degradação de carboidratos e 23 derivados da lignina. Dentre os derivados da lignina, oito compostos eram do tipo $p$-hidroxifenila, 11 compostos do tipo guaiacila e quatro compostos do tipo siringila. Nas bainhas das plantas das duas cultivares de arroz, supridas ou não com Si, a concentração de lignina (p-hidroxifenila, siringila (S) e guaiacila (G)) foi de, aproximadamente, 15\%. Houve aumento na relação S/G apenas nas bainhas das plantas da cultivar BR-Irga 409 supridas com Si e infectadas por R. solani. A maior concentração de Si nas bainhas das plantas de arroz das duas cultivares, que por sua vez resultou em aumento na relação S/G, contribuiu para reduzir os sintomas da queima das bainhas.
\end{abstract}

Palavras-chave: queima das bainhas, lignina, metabólitos secundários, resistência.

\section{Silicon altering compounds derived from the pyrolyses of leaf sheaths of rice plants infected with Rhizoctonia solani}

\begin{abstract}
This study elucidated, through analytical pyrolysis coupled to gas chromatography and mass spectrometry, changes in the chemical composition of lignin on leaf sheaths of rice plants of cultivars BR-Irga 409 and Labelle supplied or non-supplied with silicon (Si) and infected with Rhizoctonia solani. The Si concentration on leaf sheaths of plants supplied with this element

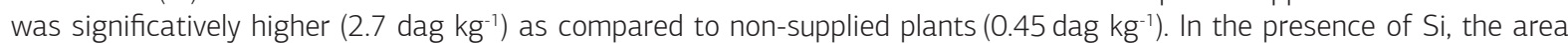
under leaf sheath blight progress curve was significantly reduced by 19 and 25\% for plants from cultivars BR-Irga 409 and Labelle, respectively, in comparison to the absence of Si. Based on the mass spectra obtained, 33 compounds were identified, 10 of which were products from the degradation of carbohydrates and 23 derivate from lignin. From lignin derivatives, eight compounds were p-hydroxiphenil type, eleven compounds were guaiacyl type and four compounds were syringyl type. On leaf sheaths of both cultivars, the concentration of lignin (p-hydroxiphenil, syringyl (S) and guaiacyl (G)) was around 15\%, regardless of Si. There was no increase in the S/G ratio only for the leaf sheaths of BR-Irga 409 supplied with Si and infected with $R$. solani. High Si concentration on leaf sheaths of both cultivars, which in turn resulted in an increase in the S/G ratio, contributed to reduce leaf sheath blight symptoms.
\end{abstract}

Key words: host resistance, lignin, secondary metabolites, sheath blight. 


\section{INTRODUÇÃO}

O arroz [Oryza sativa L.] é umas das mais importantes fontes de carboidrato para a população mundial (Greenland, 1997). A queima das bainhas, causada por Rhizoctonia solani Kühn (Thanatephorus cucumeris (A.B. Frank) Donk), é uma das principais doenças fúngicas do arroz (Ou, 1985). Lesões circulares e ou arredondadas de coloraçáo acinzentada com bordas marrom-escuras são formadas quando os escleródios do fungo entram em contato com as bainhas, germinam e o micélio forma inúmeras almofadas de infecção em sua superfície (Ou, 1985). Sob condições de alta temperatura e umidade relativa ocorrem seca parcial ou total das bainhas e folhas, acamamento das plantas, muitas glumas vazias e redução no número de perfilhos produtivos (Rush e LeE, 1992). A ocorrência de epidemias severas da queima das bainhas e a consequente redução na produção de grãos têm sido favorecidas pela irrigação por inundação, rotação de culturas com a soja e uso de cultivares altamente produtivas, mas suscetíveis à doença (Rush e LeE, 1992).

Considerando a dificuldade de se controlar a queima das bainhas, faz-se necessário a obtenção de métodos alternativos de controle. Sabe- se que o silício (Si) aumenta a resistência do arroz a diversas doenças fúngicas tais como a brusone, a mancha parda, a queima das bainhas e a escaldadura (DATNOFF et al., 2007). Em plantas de arroz de diferentes cultivares supridas com Si e submetidas à inoculaçấo com $R$. solani em diferentes estádios de desenvolvimento houve redução na intensidade da queima das bainhas (Rodrigues et al., 2001). A concentração foliar de Si em arroz pode atingir $10 \mathrm{dag} \mathrm{kg}^{-1}$ (DaLlagnol et al., 2011), sendo superior à concentraçáo dos macronutrientes nitrogênio, fósforo e potássio (MA e TAKaHASHI, 2002). O Si é absorvido pelas raízes das plantas na forma de ácido monosilícico, sendo transportado, passiva e ativamente, e depositado abaixo da cutícula formando a camada sílica-cutícula (Yoshida et al., 1962; MA et al., 2002). De acordo com KIm et al. (2002), essa dupla camada sílica-cutícula atrasou a penetração de Pyricularia grisea nas folhas de arroz (KIm et al., 2002). SCHURT et al. (2012) observaram que as bainhas obtidas das plantas das cultivares BR-Irga 409 e Labelle com concentração de Si variando de 1,9 a 2,5 dag $\mathrm{kg}^{-1}$ tinham maior força física à penetração de uma agulha, o que explicou a reduçáo no comprimento relativo das lesôes da queima das bainhas. O Si pode estar associado ao complexo lignina-carboidrato na parede celular das plantas de arroz (INANAGA et al., 1995), contribuindo para a resistência dessa planta às doenças (DATnoff et al., 2007).

A lignina, que constitui o complexo lignina-carboidrato, é um polímero fenólico, de natureza complexa, amorfo e aromático (Meier e FAIX, 1992), sintetizada nas plantas pela condensação desidrogenativa dos álcoois cinâmicos a partir da polimerização natural dos monômeros de fenilpropanoides (Meier e FaIX, 1992). A biossíntese da lignina nas plantas inicia-se pela rota dos fenilpropanoides, a partir da conversão do aminoácido fenilalanina em ácido trans-cinâmico pela enzima fenilalanina amônia-liase (Jones, 1984). Nessa rota, formam-se os álcoois $p$-cumarílico (lignina $p$-hidroxifenila), coniferílico (lignina guaiacila) e sinapílico (lignina siringila), os quais são precursores da lignina (Fengel e Wegner, 1983). Nas espécies vegetais, a lignina está presente na parede celular e na lamela média dos tecidos em uma concentração variando de 10 a $30 \mathrm{dag} \mathrm{kg}^{-1}$ (Hon e Shiraishi, 2001). A lignina é essencial para as plantas, pois fortalece a parede celular, facilita o transporte de água e previne a degradação dos tecidos por patógenos e insetos (Hatrield e Vermerris, 2001). Dependendo da planta, a constituição da lignina varia, sendo a lignina nas gramíneas diferente da lignina da madeira, por exemplo. As gramíneas contêm uma fração substancial de ácido ferúlico e p-coumarílico (Harris e Hartley, 1980) e quantidades elevadas de unidades de $p$-hidroxifenila, que é resultado da inclusão do álcool p-coumarílico junto ao álcool coniferílico e sinapílico (Harris e Hartley, 1980). Este conjunto de monômeros com radicais livres facilita a polimerização da lignina na parede celular (SARKANEN e Ludwig, 1971). De acordo com Higuchi (1990), na lignina das gramíneas ocorre a presença simultânea das unidades de $p$-hidroxifenila, guaiacila e siringila em associação com o ácido hidroxicinâmico. Essas associações ocorrem por meio de pontes éster e éter formando o complexo lignina/fenólica-carboidrato (Sun et al., 2002). Em função desta natureza química complexa, é praticamente impossível obter a lignina na sua forma pura. A lignina do tipo siringila é a mais reativa; assim, a deslignificação de madeiras com alta relação siringila/guaiacila é mais fácil de ocorrer (Tsutsumi et al., 1995).

A caracterização de materiais complexos de lignocelulose é uma das limitações nos métodos analíticos atuais. A pirólise analítica é uma técnica rápida para analisar materiais lignificados, mesmo que a cadeia de unidades da lignina seja alterada, pois os grupos de anéis aromáticos permanecem conservados (Boon, 1989). O termo pirólise significa ruptura de ligações químicas usando apenas a energia térmica. Assim, a amostra é aquecida em um ambiente inerte no qual os componentes da matriz são fragmentados. O pirolizador é acoplado a um cromatógrafo a gás (CG) juntamente com um espectrômetro de massa (EM). O CG auxilia na separação dos compostos e o EM permite suas detecçóes. A lignina, após pirolização, é uma mistura relativamente simples de fenóis que resultam de uma clivagem de éteres e determinadas ligaçôes carbonocarbono. Muitos destes fenóis conservam em suas substituiçôes padrôes do polímero de lignina, sendo possível identificar $p$-hidroxifenila, guaiacila e siringila (RALPH e Hatfield, 1991). Embora a característica química da lignina das madeiras seja bem investigada, estudos sobre as 
propriedades da lignina das gramíneas são ainda escassos (Buranov e Mazza, 2008; Scalbert et al., 1986).

Este trabalho teve como objetivo elucidar o efeito do Si na alteraçáo da composição química da lignina nas bainhas de plantas de arroz infectadas por $R$. solani.

\section{MATERIAL E MÉTODOS}

\section{Crescimento das plantas de arroz}

Sementes de arroz das cultivares BR-Irga 409 e Labelle, suscetíveis à $R$. solani, foram desinfestadas em hipoclorito de sódio $10 \%(\mathrm{v} / \mathrm{v})$ por 2 minutos, lavadas em água destilada por 3 minutos e colocadas para germinar em papel germiteste umedecido. Os rolos de papel contendo as sementes foram colocados em uma câmara de germinaçáo a $25^{\circ} \mathrm{C}$ por 6 dias no escuro. As plântulas foram crescidas em vasos plásticos com soluçáo nutritiva com todos os nutrientes em suas concentraçóes reduzidas pela metade da concentração final por sete dias. Após esse período, as plantas foram transferidas para vasos plásticos contendo 5 litros de soluçáo nutritiva de Hoagland e Arnon (1950), com modificaçóes: $1 \mathrm{mM} \mathrm{KNO}$; $0,25 \mathrm{mM}$ $\mathrm{NH}_{4} \mathrm{H}_{2} \mathrm{PO}_{4} ; 0,1 \mathrm{mM} \mathrm{NH} / 4 \mathrm{Cl} ; 0,5 \mathrm{mM} \mathrm{MgSO} .7 \mathrm{H}_{2} \mathrm{O}$; $1 \mathrm{mM} \mathrm{Ca}\left(\mathrm{NO}_{3}\right)_{2} \cdot 4 \mathrm{H}_{2} \mathrm{O} ; 0,3 \mu \mathrm{M} \mathrm{CuSO}_{4} .5 \mathrm{H}_{2} \mathrm{O} ; 0,33 \mu \mathrm{M}$ $\mathrm{ZnSO}_{4} .7 \mathrm{H}_{2} \mathrm{O} ; 11,5 \mu \mathrm{M} \mathrm{H}_{3} \mathrm{BO}_{3} ; 3,5 \mu \mathrm{M} \mathrm{MnCl}_{2} \cdot 4 \mathrm{H}_{2} \mathrm{O}$; $0,014 \mu \mathrm{M}\left(\mathrm{NH}_{4}\right)_{6} \mathrm{Mo}_{7} \mathrm{O}_{2} .4 \mathrm{H}_{2} \mathrm{O} ; 25 \mu \mathrm{M} \mathrm{Na} \mathrm{EDTA}_{2} \mathrm{e}$ $25 \mu \mathrm{M} \mathrm{FeSO} \mathrm{O}_{4} \cdot 7 \mathrm{H}_{2} \mathrm{O}$. O Si, fornecido como ácido monosilícico, foi obtido pela passagem do silicato de potássio através de resina de troca de cátions (Amberlite IR-120B, $\mathrm{H}^{+}$forma, Sigma-Aldrich, São Paulo) (Ma et al., 2002). As concentrações de Si utilizadas foram de 0 e $2 \mathrm{mM}$. A cada quatro dias a soluçáo nutritiva foi trocada e o $\mathrm{pH}$ foi aferido a cada dois dias e mantido entre 5,5 e 6 .

\section{Inoculação com R. solani e avaliação da doença}

As bainhas das plantas foram submetidas à inoculaçáo com R. solani aos 60 dias após o transplantio (estádio de máximo perfilhamento) para a solução nutritiva. Utilizou-se o isolado de $R$ s solani CNPAF $R s-1$ (AG-1 IA) fornecido pelo Dr. Anne Sitarama Prabhu da Empresa Brasileira de Pesquisa Agropecuária - Centro Nacional de Pesquisa de Arroz e Feijão (EMBRAPA-CNPAF). Escleródios do fungo foram preservados em sílica gel. Após o crescimento do fungo em meio de cultura batata-dextrose-ágar (BDA), obtido a partir de escleródios, transferiram-se discos do meio contendo micélio para novas placas de Petri contendo BDA. Na superfície do meio de cultura contido em cada placa de Petri, colocaram-se pedaços de palito de dente de, aproximadamente, $1 \mathrm{~cm}$ de comprimento, que serviram como suporte para o crescimento do fungo. Os pedaços de palito de dente, previamente lavados em água quente para remover possíveis substâncias tóxicas, foram colocados em frascos contendo BDA e autoclavados por 20 minutos, de acordo com método descrito por Rodrigues et al. (2001). As placas contendo micélio crescendo sobre e também no interior dos palitos permaneceram em câmara de crescimento $\left(25^{\circ} \mathrm{C}\right.$, fotoperíodo de 12 horas) por cinco dias. A segunda bainha do colmo principal de cada planta foi submetida à inoculação colocando, com auxílio de uma pinça estéril, um pedaço de palito colonizado pelo fungo. As bainhas inoculadas foram amarradas aos perfilhos das plantas com fitilhos. Imediatamente após a inoculação, as plantas foram transferidas para uma câmara de nevoeiro (temperatura de $25 \pm 2{ }^{\circ} \mathrm{C}$ e umidade relativa de $90 \pm 5 \%$ ). Avaliou-se o comprimento da lesão em cada bainha inoculada às $24,48,72$, 96 e 120 horas após inoculação (hai) com o auxílio de um paquímetro digital e calculou-se o comprimento relativo da lesão $(\mathrm{CRL})$ dividindo o comprimento da lesão $(\mathrm{cm})$ pelo comprimento da bainha $(\mathrm{cm}) \times 100$. O comprimento das bainhas foi padronizado em $15 \mathrm{~cm}$. Os dados do CRL foram utilizados para calcular a área abaixo da curva do progresso do comprimento relativo da lesão (AACPCRL) pela integração trapezoidal das curvas de progresso do CRL, de acordo com método de Shaner e FinNey (1977).

\section{Determinação da concentração de Si na bainha}

As bainhas das plantas foram coletadas às 125 hai, secas em estufa a $65^{\circ} \mathrm{C}$ por quatro dias até atingirem massa constante. Após este procedimento, elas foram moídas em moinho tipo Wiley para determinação da concentração de Si pelo método de Korndörfer et al. (2004).

\section{Preparo das amostras para pirólise e quantificação dos derivados de carboidratos e da lignina}

Coletaram-se todas as bainhas do colmo principal das plantas submetidas à inoculação com $R$. solani às 120 hai $\mathrm{e}$ também de plantas não infectadas com o fungo das repetiçôes de cada tratamento. Durante as coletas, as bainhas foram congeladas em nitrogênio líquido e armazenadas em ultrafreezer a $-80^{\circ} \mathrm{C}$. As amostras das bainhas foram liofilizadas, moídas em moinho tipo Thomas-Wiley e o pó fino obtido foi passado em peneira de 40 mesh. O pó obtido de cada amostra de bainha (aproximadamente $100 \mu \mathrm{g}$ ) foi colocado em cadinho de platina e pirolisado nas temperaturas de $300,400,500,550$ e $600{ }^{\circ} \mathrm{C}$ por 10 segundos. Para pirolisar, utilizou-se um microforno vertical (PYR-4A Shimadzu) acoplado a um cromatógrafo a gás e espectrômetro de massa Pi-CG-EM (PQ5050A, Shimadzu). Os produtos da pirólise foram automaticamente injetados no 
cromatógrafo utilizando-se como gás de arraste o hélio, na razão de fluxo de $1 \mathrm{~mL} \mathrm{~min}^{-1}$ e razão de split 1/10 e o fluxômetro eletrônico modelo Veri-Flow 500 (Agilet). Para a separaçáo dos compostos obtidos, utilizou-se coluna capilar de sílica fundida DB-5 (30 m × 0,25 mm de diâmetro $\times 0,25 \mu \mathrm{m}$ de filme). A temperatura inicial da coluna foi de $45^{\circ} \mathrm{C}$ por 4 minutos aumentando de 45 até $240^{\circ} \mathrm{C}$ na taxa de $4{ }^{\circ} \mathrm{C} \mathrm{min}^{-1}$, permanecendo nessa temperatura por 10 minutos. A temperatura do detector foi de $250{ }^{\circ} \mathrm{C}$ e na inferface CG-EM de $290^{\circ} \mathrm{C}$. O detector de massas operou por ionização por impacto de elétrons $(70 \mathrm{eV})$ e varredura de massas no intervalo de m/z 40 a $400 \mathrm{Da}$. Os compostos foram identificados através da comparação dos espectros de massas das amostras com o banco de dados contidos no software do aparelho (Wiley, 7. a edição), utilizando-se o modo de fragmentação das moléculas e a comparação com a literatura. A quantificação dos derivados de carboidratos e da lignina foi baseada nas áreas dos picos obtidos, cuja soma correspondeu a $100 \%$. A porcentagem da área dos derivados da lignina tais como $p$-hidroxifenila, guaiacila e siringila correspondeu ao somatório das áreas das unidades destes três derivados. A área dos derivados totais da lignina foi o somatório das áreas dos derivados de lignina tais como $p$-hidroxifenila, guaiacila e siringila. A relação siringila/ guaiacila $(\mathrm{S} / \mathrm{G})$ foi determinada pela razão dos somatórios das áreas relativas aos sinais correspondentes às estruturas siringila e guaiacila.

\section{Delineamento experimental e análise estatística dos dados}

O experimento foi instalado em delineamento inteiramente casualizado em esquema fatorial $2 \times 2$, com 15 repetições. Os fatores estudados foram as duas cultivares de arroz e a presença $(+\mathrm{Si})$ ou ausência $(-\mathrm{Si})$ de $\mathrm{Si}$ na solução nutritiva. Cada repetição correspondeu a um vaso plástico contendo duas plantas de arroz. Para as amostras pirolizadas, das 15 repetiçôes de cada tratamento, obtiveram-se três amostras compostas para pirolização. Os dados da AACPCRL e da concentração de Si na bainha foram submetidos à análise de variância e as médias dos tratamentos comparadas pelo teste de Tukey $(\mathrm{p} \leq 0,05)$, utilizando-se o programa SAS 9.0 (SAS Institute). Os dados da análise de pirólise foram interpretados qualitativamente.

Tabela 1. Área abaixo da curva do progresso do comprimento relativo da lesão (AACPCRL) da queima das bainhas nas cultivares BR-Irga 409 e Labelle supridas $(+\mathrm{Si})$ ou não $(-\mathrm{Si})$ com silício $(\mathrm{Si})$

\begin{tabular}{|c|c|c|}
\hline \multirow{2}{*}{ Cultivares } & \multicolumn{2}{|c|}{ AACPCRL } \\
\hline & $-\mathbf{S i}$ & $+\mathrm{Si}$ \\
\hline BR-Irga 409 & 2938 aA & $2378 \mathrm{aB}$ \\
\hline Labelle & $2632 \mathrm{aA}$ & 1968 bB \\
\hline CV (\%) & & \\
\hline
\end{tabular}

Médias seguidas pela mesma letra, minúscula na coluna e maiúscula na linha, não diferem entre si pelo teste de Tukey a $5 \%$ de probabilidade. CV = coeficiente de variação.

\section{RESULTADOS E DISCUSSÃO}

Não houve diferença estatística entre as plantas das cultivares BR-Irga 409 e Labelle náo supridas com Si para a AACPCRL (Tabela 1). Na presença de Si, a AACPCRL foi significativamente reduzida em $17 \%$ para as plantas da cultivar Labelle em relação às plantas da cultivar BR-Irga 409 (Tabela 1). Na presença de $\mathrm{Si}$, a AACPCRL foi reduzida significativamente em 19 e $25 \%$, respectivamente, para as plantas das cultivares BR-Irga-409 e Labelle, em relação à ausência desse elemento na solução nutritiva (Tabela 1). Não houve diferença significativa para a concentração de Si nas bainhas entre as plantas das cultivares BR-Irga 409 e Labelle supridas ou não com $\mathrm{Si}$. $\mathrm{Na}$ presença de $\mathrm{Si}$, as concentraçóes desse elemento na bainha foram de 2,9 e 2,5 dag kg-1, respectivamente, para as cultivares BR-Irga 409 e Labelle. Para as cultivares BR-Irga 409 e Labelle não supridas com $\mathrm{Si}$, as concentrações desse elemento na bainha foram de 0,5 e $0,4 \mathrm{dag}_{\mathrm{kg}^{-1}}$ respectivamente. A concentração de Si nas bainhas das plantas supridas com Si foi significativamente maior $\left(2,7 \mathrm{dag} \mathrm{kg}^{-1}\right)$ em comparação com as plantas não supridas com esse elemento

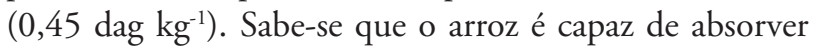
até 10 dag de Si por kg de matéria seca (Dallagnol et al., 2011). Rodrigues et al. (2001) obtiveram aumento de $80 \%$ para a concentração de Si nas bainhas das plantas de seis cultivares de arroz, resultando em decréscimo na área abaixo da curva do progresso da extensão da lesão da queima das bainhas. WinsLow et al. (1992) reportaram que o Si somente reduziu a severidade da queima das bainhas nos genótipos de arroz irrigado do tipo indica, enquanto Rodrigues et al. (2001) demonstraram que cultivares de arroz tanto do tipo indica quanto japonica, supridas com $\mathrm{Si}$, tiveram redução na severidade da queima das bainhas.

Com o objetivo de determinar a melhor temperatura para a pirolização, realizou-se a pirólise do pó das bainhas das plantas de arroz apenas da cultivar BR-Irga 409 não supridas com $\mathrm{Si}$. As melhores temperaturas para a pirólise das amostras foram de 500 e $550^{\circ} \mathrm{C}$ decorrentes da maior quantidade de compostos obtidos (Figura 1). Nos espectros de massas, os derivados da lignina forneceram íons moleculares intensos de até $100 \%$. Os carboidratos foram facilmente fragmentados no impacto eletrônico, formando íons de baixa massa molecular e, consequentemente, de difícil identificação.

A comparação dos espectros de massa obtidos da pirolização das bainhas das plantas das cultivares BR-Irga 409 e Labelle supridas ou não com Si e inoculadas ou não com $R$. solani (Figura 2) com os dados da literatura permitiu a identificação de 33 compostos (Tabela 2). A análise desses compostos permitiu agrupá-los em 10 compostos originados da degradação de carboidratos e 23 derivados da lignina. Dentre os 23 compostos derivados de lignina, oito tiveram origem do tipo $p$-hidroxifenila, 11 do tipo guaiacila e quatro do tipo siringila. Alguns compostos não 


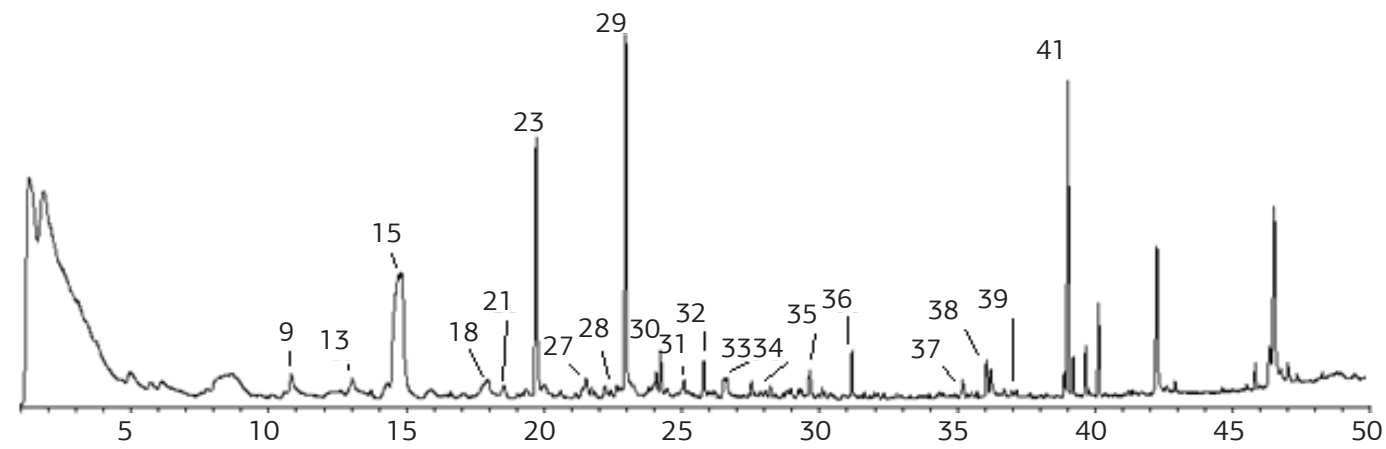

(a)

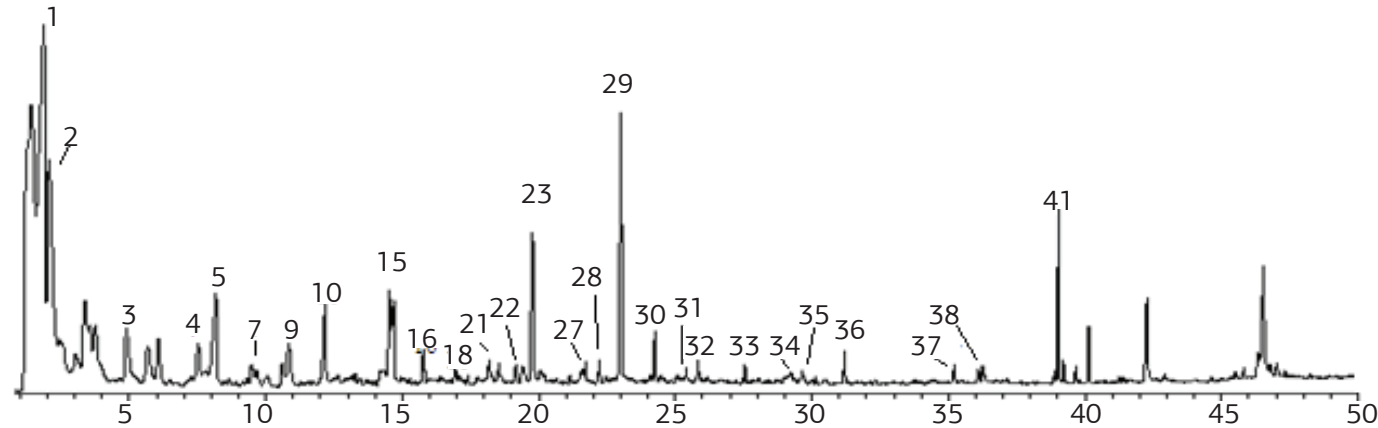

(b)

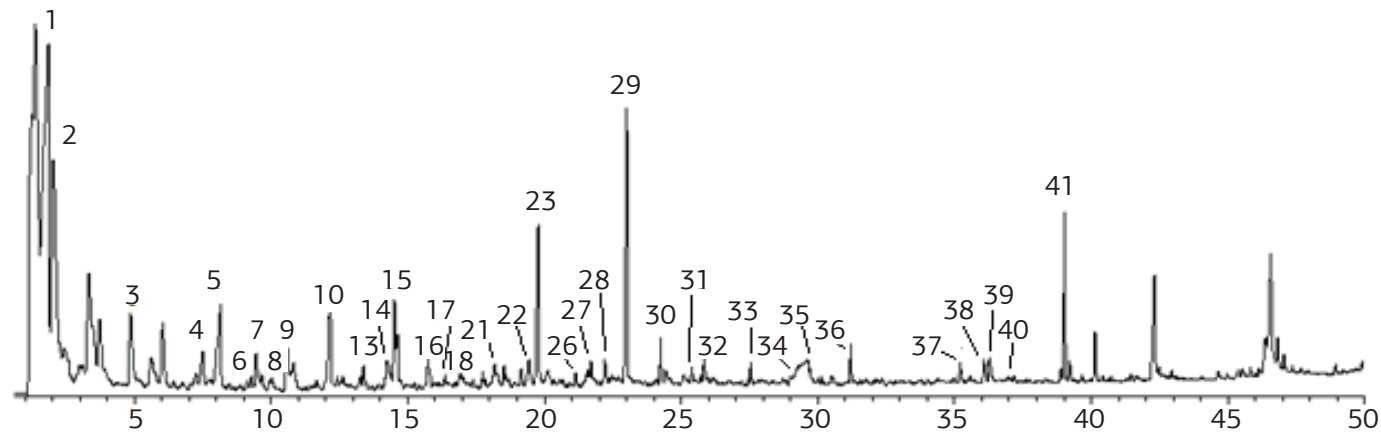

(c)

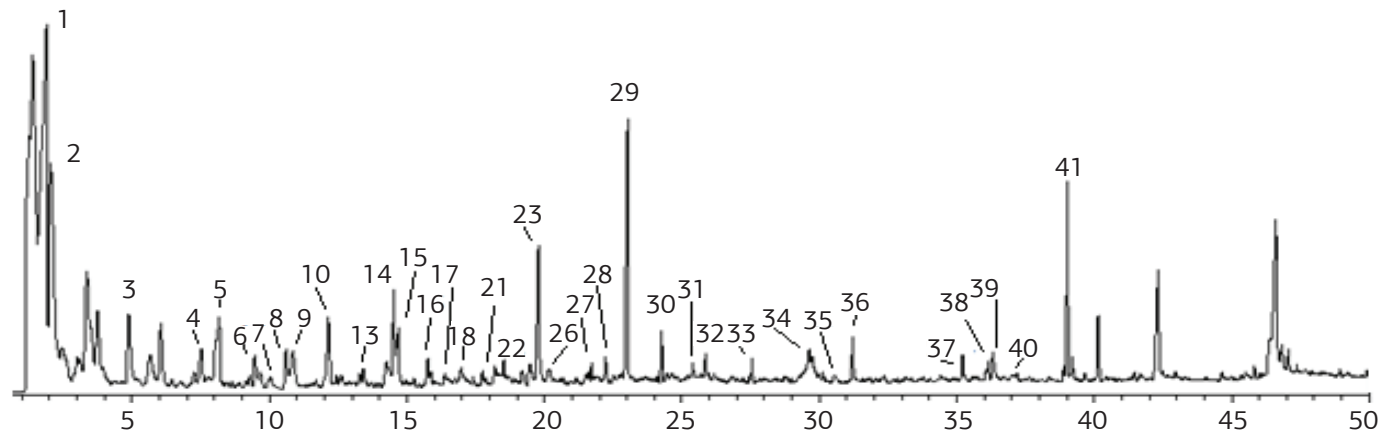

(d)

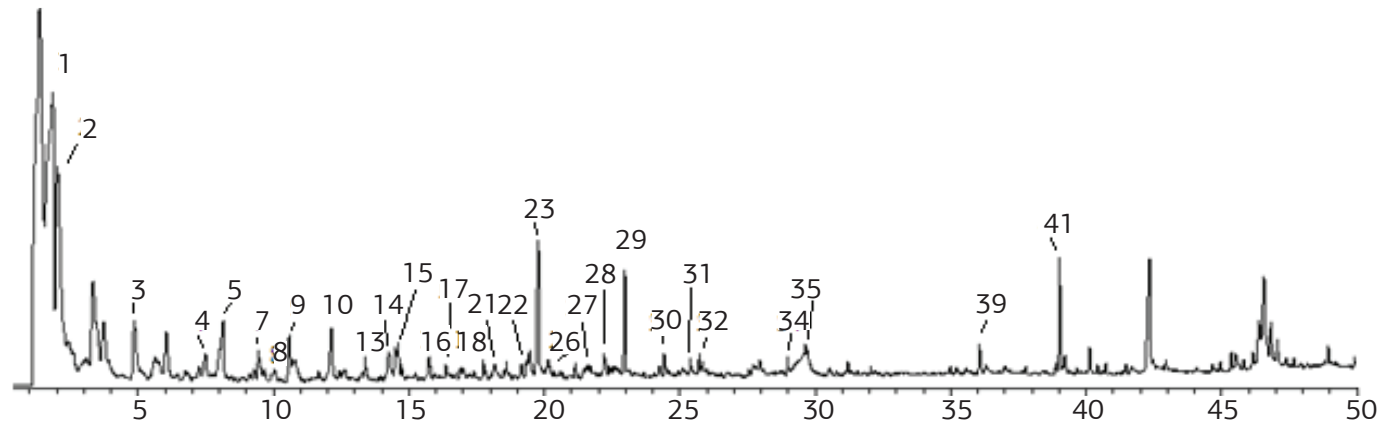

(e)

Figura 1. Pirogramas do pó das bainhas de plantas de arroz da cultivar BR-Irga 409 não supridas com silício. As amostras foram pirolizadas nas temperaturas de 300 (a), 400 (b), 500 (c), 550 (d) e $600^{\circ} \mathrm{C}$ (e). Os números para os picos em cada pirograma referem-se aos compostos apresentados na tabela 2 . 
foram identificados em decorrência da baixa resoluçáo dos seus espectros de massas. Entretanto, ao analisarem amostras de bainhas de arroz pirolizadas a $500^{\circ} \mathrm{C}$ durante 4 s, Kuroda et al. (1995) identificaram 16 compostos, dos quais cinco tiveram origem do tipo $p$-hidroxifenila, seis do tipo guaiacila e cinco do tipo siringila.

Ao analisar os compostos obtidos (Tabela 2), três deles (4-metil-2(5H)-furanona, 3-metil-indole e siringaldeído) foram observados nas bainhas das plantas da cultivar Labelle, sendo ausentes na cultivar BR-Irga 409. Os compostos 2,6-dimetilfenol, 4-etilfenol, ácido p-coumárico e 3-isopropilfenol foram constatados apenas nas amostras das bainhas da cultivar BR-Irga 409. Sabe-se que o colmo do arroz é de composição química heterogênea e complexa e possui variações em função da parte analisada (JIN e CHEN, 2006) e também do tipo da cultivar (Summers et al., 2003).

No presente estudo, observou-se nas bainhas das plantas de arroz, supridas ou não com $\mathrm{Si}$, derivados da lignina em uma faixa de 4,9 a 9,2\% da área para o tipo $p$-hidroxifenila; entre 4,2 e 6,1\% para a guaiacila e de 0,7 e 1,1\% para a siringila. A soma das áreas desses derivados da lignina foi de, aproximadamente, 15\%. Esses resultados estão dentro da faixa verificada em outros trabalhos como o de Deng et al. (2007).

A lignina da bainha do arroz possui unidades de $p$-hidroxifenila, guaiacila e siringila, respectivamente, nas proporçốes de 56, 37 e 7\%. De acordo com Lapiere et al. (1993), as proporçôes das unidades $p$-hidroxifenila, guaiacila e siringila no colmo de plantas de arroz foram de, respectivamente, 15,45 e $40 \%$. O uso de diferentes métodos, estágio fenológico da planta e as partes da planta analisada podem ter contribuído para tais variaçóes, como provado por Lewis e Yамамото (1990).

No presente estudo, houve aumento na relação $S / G$, exceto para as bainhas das plantas da cultivar BR-Irga 409 supridas com Si (Tabela 3), o que pode representar uma possível reaçáo de defesa das plantas à infecção por $R$. solani. De acordo com Ride (1995), os aumentos na concentração de siringila durante a maturação das gramíneas as tornam mais resistentes à infecção por patógenos fúngicos. Nas bainhas das plantas da cultivar Labelle, supridas ou não com $S i$, a relação $S / G$ foi maior em comparação com as bainhas das plantas da cultivar BR-Irga 409 (Tabela 3). O mesmo foi observado para as plantas dessas duas cultivares não submetidas à inoculação com $R$. solani.

Nas bainhas das plantas da cultivar BR-Irga 409 inoculadas com $R$. solani, as áreas dos derivados da lignina do tipo $p$-hidroxifenila foram maiores em, aproximadamente, $57 \%$ em relação a cultivar Labelle. Nas bainhas das plantas da cultivar BR-Irga 409 infectadas por $R$. solani houve aumento de até $10 \%$ nas áreas dos derivados da lignina do tipo $p$-hidroxifenila em relação às plantas não inoculadas. Uma hipótese para a maior resistência da cultivar Labelle à infecção por $R$. solani em relação a cultivar BR-Irga-409 é a produçâo pela planta de outros compostos de defesa não identificados na pirolização. KunodA et al. (1995) observaram que em amostras de bainhas e de folhas de arroz analisadas por Pi-CG-EM houve maior concentração de derivados da lignina do tipo $p$-hidroxifenila. Para as duas cultivares supridas com $\mathrm{Si}$, não houve aumento na soma das áreas dos derivados totais da lignina, o que pode ser explicado pelo gasto energético na absorção do Si.
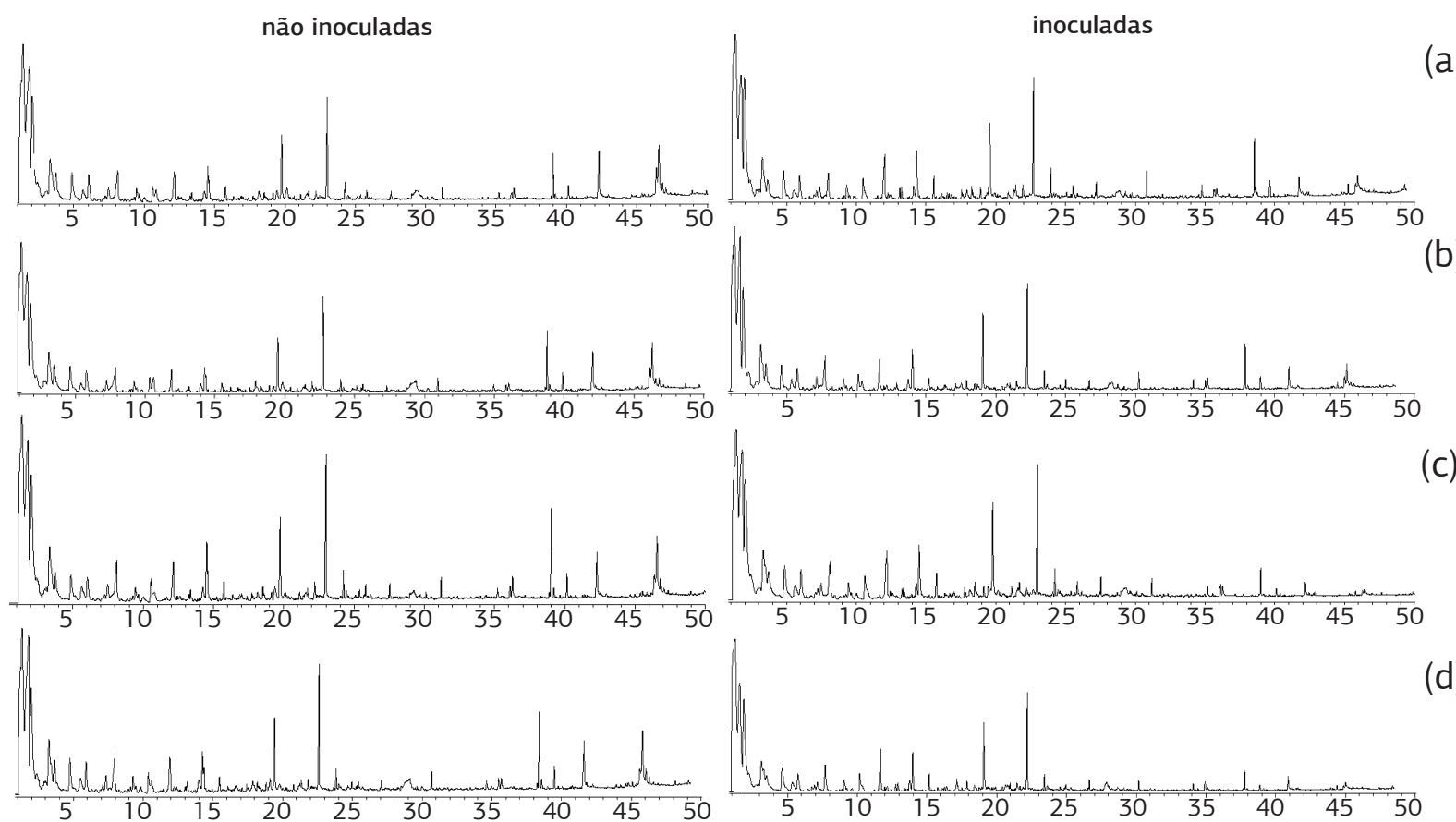

(a)

Figura 2. Pirogramas do pó das bainhas obtidas das plantas das cultivares BR-Irga 409 (a,b) e Labelle (c,d) inoculadas ou não com Rhizoctonia solani e supridas $(\mathrm{b}, \mathrm{d})$ ou não supridas $(\mathrm{a}, \mathrm{c})$ com silício. As amostras das bainhas inoculadas com R. solani foram obtidas às 120 horas após a inoculação. 
Tabela 2. Compostos fenólicos identificados pela técnica da pirólise nas bainhas das plantas de arroz das cultivares Labelle e BR-Irga 409 supridas $(+\mathrm{Si})$ ou não supridas $(-\mathrm{Si})$ com silício $(\mathrm{Si})$ e inoculadas ou não inoculadas com Rhizoctonia solani

\begin{tabular}{|c|c|c|c|c|c|c|c|c|c|c|c|}
\hline \multirow{4}{*}{$\operatorname{Picos}(1)$} & \multirow{4}{*}{$\operatorname{TR}^{(2)}$} & \multirow{4}{*}{ Nomes dos compostos } & \multicolumn{8}{|c|}{ Áreas relativas (\%) } & \multirow{4}{*}{ Origens $^{(3)}$} \\
\hline & & & \multicolumn{4}{|c|}{ Labelle } & \multicolumn{4}{|c|}{ BR-Irga 409} & \\
\hline & & & \multicolumn{2}{|c|}{$\begin{array}{c}\text { Não } \\
\text { inoculadas }\end{array}$} & \multicolumn{2}{|c|}{ Inoculadas } & \multicolumn{2}{|c|}{$\begin{array}{c}\text { Não } \\
\text { inoculadas }\end{array}$} & \multicolumn{2}{|c|}{ Inoculadas } & \\
\hline & & & $+\mathrm{Si}$ & $-\mathrm{Si}$ & $+\mathrm{Si}$ & $-S i$ & $+\mathrm{Si}$ & $-\mathbf{S i}$ & $+\mathrm{Si}$ & $-\mathbf{S i}$ & \\
\hline 1 & 1,26 & $\mathrm{NI}$ & 8,64 & 10,06 & 15,24 & 10,09 & 11,44 & 9,44 & 11,28 & 14,06 & $\mathrm{Nd}$ \\
\hline 2 & 1,37 & Ácido acético & 14,50 & 16,23 & 18,50 & 16,23 & 18,61 & 17,27 & 18,01 & 19,87 & C \\
\hline 3 & 4,84 & Furfurol & 1,83 & 1,37 & 1,84 & 1,91 & 2,02 & 1,71 & 1,93 & 1,73 & C \\
\hline 4 & 7,46 & Furan-2(5H)-ona & 0,82 & 0,95 & 0,70 & 0,80 & 0,68 & 0,71 & 0,73 & 0,67 & C \\
\hline 5 & 8,09 & Furan-2(2H)-ona & 1,86 & 2,22 & 2,17 & 2,29 & 1,83 & 1,81 & 2,24 & 1,78 & C \\
\hline 6 & 9,02 & Furan-2,6(3H,4H)-dione & 0,70 & 0,68 & 0,80 & 0,73 & 0,10 & 0,10 & 0,14 & 0,24 & C \\
\hline 7 & 9,53 & 3-Furanona & 0,33 & 0,30 & 0,24 & 0,24 & 0,79 & 0,49 & 0,76 & 0,54 & C \\
\hline 8 & 9,94 & 4-Metil-2(5H)-furanona & 0,14 & 0,14 & 0,12 & 0,16 & - & - & - & - & C \\
\hline 9 & 10,55 & Monofenol & 0,83 & 0,73 & 1,17 & 1,19 & 1,01 & 0,88 & 1,09 & 1,03 & $\mathrm{LH}$ \\
\hline 10 & 12,12 & 2-hidroxil-3-metil-2-ciclopenteno-1-ona & 1,74 & 1,70 & 1,79 & 2,28 & 1,12 & 1,45 & 1,95 & 2,16 & C \\
\hline 11 & 13,34 & 2-Metilfenol & 0,25 & 0,27 & 0,31 & 0,18 & 0,15 & 0,27 & 0,27 & 0,30 & LG \\
\hline 12 & 14,09 & 4-Metilfenol & 0,71 & 0,62 & 0,36 & 0,40 & 0,77 & 0,51 & 0,83 & 0,58 & LG \\
\hline 13 & 14,49 & Guaiacol & 1,49 & 2,12 & 2,09 & 2,13 & 1,15 & 1,46 & 1,99 & 2,31 & LG \\
\hline 14 & 15,71 & 6-diidro-metil-2H-piran-3(4H)-ona & 0,49 & 0,52 & 0,69 & 0,70 & 0,48 & 0,54 & 0,60 & 0,66 & C \\
\hline 15 & 16,81 & Valerolactona & 0,05 & 0,17 & 0,18 & 0,14 & 0,12 & 0,15 & 0,19 & 0,19 & $\mathrm{Nd}$ \\
\hline 16 & 16,90 & 3,5-dimetilfenol & 0,22 & 0,12 & 0,17 & 0,13 & 0,12 & 0,15 & 0,17 & 0,24 & LH \\
\hline 17 & 16,98 & 2,6-dimetilfenol & - & - & - & - & 0,17 & 0,14 & 0,13 & 0,14 & $\mathrm{LH}$ \\
\hline 18 & 17,68 & 4-etilfenol & - & - & - & - & 0,16 & 0,12 & 0,20 & 0,19 & LH \\
\hline 19 & 17,78 & 3-etilfenol & 0,15 & 0,14 & 0,36 & 0,22 & 0,09 & 0,08 & 0,13 & 0,24 & LH \\
\hline 20 & 18,45 & 4-metilguaiacol & 0,19 & 0,30 & 0,30 & 0,36 & 0,36 & 0,18 & 0,29 & 0,23 & LG \\
\hline 21 & 19,34 & Pirocatecol & 0,66 & 0,67 & 0,21 & 0,77 & 0,47 & 0,70 & 0,46 & 0,35 & LG \\
\hline 22 & 19,69 & Ácido 4-coumárico & - & - & - & - & 3,13 & 2,61 & 3,81 & 3,29 & LH \\
\hline 23 & 20,15 & 3-isopropilfenol & - & - & - & - & 0,09 & 0,64 & - & 0,07 & $\mathrm{LH}$ \\
\hline 24 & 21,11 & 3-metil-pirocatecol & 0,12 & 0,22 & 0,40 & 0,31 & 0,12 & 0,20 & 0,19 & 0,16 & LG \\
\hline 25 & 21,68 & 4-etilguaiacol & 0,20 & 0,21 & 0,18 & 0,30 & 0,17 & 0,21 & 0,22 & 0,21 & LG \\
\hline 26 & 22,18 & 2,3-benzopirole & 0,29 & 0,42 & 0,30 & 0,19 & 0,29 & 0,25 & 0,29 & 0,23 & $\mathrm{Nd}$ \\
\hline 27 & 22,97 & 4-etil-2-metoxil-fenol & 4,12 & 3,97 & 3,51 & 3,88 & 3,78 & 3,48 & 3,75 & 3,89 & LH \\
\hline 28 & 24,22 & Siringol & 0,54 & 0,63 & 0,54 & 0,66 & 0,41 & 0,54 & 0,55 & 0,66 & LS \\
\hline 29 & 25,38 & 3-metil-indole & 0,15 & 0,16 & 0,09 & 0,08 & - & - & - & - & $\mathrm{Nd}$ \\
\hline 30 & 25,80 & Vanilina & 0,29 & 0,32 & 0,20 & 0,44 & 0,24 & 0,25 & 0,30 & 0,26 & LG \\
\hline 31 & 27,43 & Metilsiringol & 0,06 & 0,06 & 0,07 & 0,10 & 0,05 & 0,07 & 0,08 & 0,12 & LS \\
\hline 32 & 27,52 & Isoeugenol & 0,26 & 0,35 & 0,29 & 0,43 & 0,19 & 0,29 & 0,31 & 0,35 & LG \\
\hline 33 & 28,93 & Levoglicosano & 0,14 & 0,05 & 0,76 & 0,06 & 0,07 & 0,42 & 0,31 & 0,28 & C \\
\hline 34 & 29,56 & 2,4-di-tert-butilfenol & 0,15 & 0,20 & 0,10 & 0,13 & 0,09 & 0,15 & 0,14 & 0,13 & $\mathrm{Nd}$ \\
\hline 35 & 34,00 & Siringaldeido & 0,04 & 0,06 & 0,04 & 0,06 & - & - & - & - & LS \\
\hline 36 & 35,18 & Metoxieugenol & 0,27 & 0,22 & 0,20 & 0,23 & 0,22 & 0,21 & 0,24 & 0,26 & LG \\
\hline 37 & 36,06 & Acetosiringol & 0,27 & 0,43 & 0,37 & 0,43 & 0,28 & 0,27 & 0,27 & 0,25 & LS \\
\hline 38 & 36,23 & Álcool coniferílico & 0,39 & 0,67 & 0,27 & 0,59 & 0,36 & 0,46 & 0,37 & 0,37 & LG \\
\hline 39 & 38,99 & Neofitodieno & 1,92 & 1,96 & 0,60 & 0,70 & 1,91 & 1,22 & 1,06 & 1,15 & $\mathrm{Nd}$ \\
\hline \multicolumn{3}{|c|}{ Área dos derivados de carboidratos (\%) } & 22,56 & 24,17 & 27,61 & 25,40 & 25,70 & 24,50 & 26,68 & 27,93 & \\
\hline \multicolumn{3}{|c|}{ Lignina tipo $p$-hidroxifenila (\%) } & 5,31 & 4,96 & 5,20 & 5,42 & 8,54 & 8,10 & 9,28 & 9,09 & \\
\hline \multicolumn{3}{|c|}{ Lignina tipo guaiacila (\%) } & 4,83 & 5,97 & 4,81 & 6,13 & 4,22 & 4,76 & 5,48 & 5,39 & \\
\hline \multicolumn{3}{|c|}{ Lignina tipo siringila (\%) } & 0,90 & 1,18 & 1,03 & 1,24 & 0,74 & 0,88 & 0,91 & 1,03 & \\
\hline \multicolumn{3}{|c|}{ Área dos derivados totais da lignina (\%) } & 11,04 & 12,11 & 11,04 & 12,79 & 13,50 & 13,74 & 15,66 & 15,51 & \\
\hline
\end{tabular}

(1) O número do pico refere-se aos sinais designados na Figura 1d. $\left({ }^{2}\right)$ Tempo de retençáo, em minutos, do composto na coluna. $\left({ }^{3}\right)$ Origem do composto. NI = composto nấo identificado; $\mathrm{C}=$ carboidratos; $\mathrm{LH}=$ lignina $p$-hidroxifenila; $\mathrm{LG}=$ lignina guaiacila; $\mathrm{LS}$ = lignina siringila; - = composto não detectado; nd = composto năo determinado. As bainhas foram coletadas de plantas não inoculadas com Rhizoctonia solani e de plantas às 120 horas após inoculaçáo.

Porém, nas plantas infectadas por $R$. solani e não supridas com $\mathrm{Si}$, houve aumento na área dos derivados da lignina, indicando uma reação da planta à infecção pelo patógeno.

Segundo Dallagnol et al. (2011), a concentraçáo de derivados da lignina-ácido tioglicólico (DLATG) em plantas de arroz não supridas com $\mathrm{Si}$ e infectadas por Bipolaris oryzae foi menor do que a concentração obtida para as plantas supridas com esse elemento. Resultados semelhantes foram obtidos por Rodrigues et al. (2005) para o patossistema arroz-Pyricularia grisea, cujas concentraçôes 
Tabela 3. Relaçóes siringila/guaiacila nas bainhas das plantas de arroz das cultivares Labelle e BR-Irga 409 supridas $(+\mathrm{Si})$ ou não $(-\mathrm{Si})$ supridas com silício $(\mathrm{Si})$ e inoculadas ou não inoculadas com Rhizoctonia solani

\begin{tabular}{lcccc}
\multirow{2}{*}{ Tratamentos } & \multicolumn{2}{c}{ Labelle } & \multicolumn{2}{c}{ BR-Irga 409} \\
\cline { 2 - 5 } & $+\mathrm{Si}$ & $-\mathrm{Si}$ & $+\mathrm{Si}$ & $-\mathrm{Si}$ \\
Bainhas não & 0,187 & 0,197 & 0,175 & 0,186 \\
inoculadas & 0,213 & 0,202 & 0,166 & 0,191
\end{tabular}

de DLATG foram maiores nas folhas das plantas não supridas com Si do que nas plantas supridas com esse elemento. A concentração de lignina em plantas de arroz supridas com $\mathrm{Si}$ e suscetíveis à brusone foi maior do que nas plantas resistentes a essa doença (CAI et al., 2008). Não houve diferença para a concentração de lignina entre as plantas de arroz infectadas por $P$. grisea independente da presença de Si (CAI et al., 2008).

Para a área dos derivados de carboidratos (Tabela 2), observou-se que nas bainhas das plantas supridas ou não com Si e infectadas por $R$. solani, houve aumento de, aproximadamente, 9,5\%. A análise das áreas dos derivados de carboidratos e da lignina total nas bainhas das plantas das duas cultivares, supridas ou não com $\mathrm{Si}$, mostrou que, aproximadamente, $66 \% \mathrm{da}$ área foi de derivados de carboidratos, mesmo considerando que essas amostras não estiveram livres de extrativos em sua constituição. Azuma e Koshimjima (1988) analisaram colmos de plantas de arroz livres de extrativos e observaram $64 \%$ de carboidratos em relação à lignina. $\mathrm{O}$ ácido $p$-coumárico somente foi constatado nas bainhas das plantas da cultivar BR-Irga 409. Observou-se aumento da área do ácido $p$-coumárico nas amostras das bainhas infectadas por $R$. solani (Tabela 2), mesmo embora a importância desse tipo de composto fenólico na parede celular ainda não seja bem compreendida (LewIS e YAMAMOTO, 1990).

\section{CONCLUSÃO}

A resistência do arroz à queima das bainhas aumenta nas plantas das cultivares BR-Irga 409 e Labelle supridas com Si. O aumento da relação siringila/guaiacila nos tecidos das bainhas das cultivares de arroz supridas com Si, principalmente para a cultivar Labelle, contribui para o aumento da resistência à queima das bainhas.

\section{AGRADECIMENTOS}

Os professores F.A. Rodrigues e N.F.F. Soares agradecem ao Conselho Nacional de Desenvolvimento Científico e Tecnológico (CNPq) pelas bolsas de produtividade em pesquisa. Dr. D.A. Schurt agradece à FAPEMIG pela bolsa de Doutorado. Os autores agradecem à CAPES, ao CNPq e à FAPEMIG pelo recurso financeiro e ao Dr. Flaviano Oliveira Silvério pela leitura do manuscrito.

\section{REFERÊNCIAS}

AZUMA, J.; KOSHIMJIMA T. Lignin-carbohydrate complexes from various sources. Methods in Enzymology, v.161, p.12-18, 1988.

BURANOV, A.U.; MAZZA, G. Lignin in straw of herbaceous crops. Industrial Crops and Products, v.28, p.237-259, 2008.

BURRITT, E.A.; BITTNER, A.S.; STREET, J.C.; ANDERSON, M.J. Correlations of phenolic acids and xylose content of cell wall with in vitro dry matter digestibility of three maturing grasses. Journal of Dairy Science, v.67, p.1209-1210, 1984.

BOON, J.J. An introduction to pyrolysis mass spectrometry of lignocellulosic materials: Case studies on barley straw, corn stem and agropyron. In: CHESSON A, ORSKOV E.R. (Ed.). Physico-Chemical Characterization of Plant Residues for Industrial and Feed Use. London: Elsevier Applied Science, 1989. p.25-49.

CAI, K.; GAO, D.; LUO, S.; ZENG, R.; YANG, J.; ZHU, X. Physiological and cytological mechanisms of silicon-induced resistance in rice against blast disease. Physiologia Plantarum, v.134, p.324-333, 2008.

DATNOFF, L.E.; RODRIGUES, F.A.; SEEBOLD, K.W. Silicon and plant diseases. In: DATNOFF, L.E.; ELMER, W.H.; HUBER, D.M. (Ed.). Mineral Nutrition and Plant Diseases. St. Paul: APS Press, 2007. p.233-246.

DALLAGNOL, L.J.; RODRIGUES, F.A.; DAMATTA, F.M.; MIELLI, M.V.B.; PEREIRA, S.C. Deficiency in silicon uptake affects cytological, physiological, and biochemical events in the rice interaction. Phytopathology, v.101, p.92-104, 2011.

DENG, L.; WANG, Y.; ZHANG, Y.; MA, R. The enhancement of ammonia pre-treatment on the fermentation of rice straw hydrolysate to xylitol. Journal of Food Biochemistry, v.31, p.195-205, 2007.

FENGEL, D.E.; WEGNER, G. Wood chemistry, ultrastructure and reactions. Berlim-New York: Walter de Gruyter, 1983. 613p.

GREENLAND, D.J. The sustainability of rice farming. Wallingford: CAB International, 1997. 273p.

HARRIS, P.J.; HARTLEY, R.D. Phenolic constituents of the cell walls of monocotyledons. Biochemical Systematics and Ecology, v.8, p.153-160, 1980.

HATFIELD, R.; VERMERRIS, W. Lignin Formation in Plants. The Dilemma of Linkage Specificity. Plant Physiology, v.126, p.1351-1357, 2001.

HIGUCHI, T. Lignin Biochemistry: Biosynthesis and Biodegradation. Wood Science Technology, v.24, p.23-63, 1990.

HOAGLAND, D.R.; ARNON, D.I. The water culture method for growing plant without soil. California Agricultural Experiment Station Circular, v.347, p.1-32. 1950.

HON, D.N.S.; SHIRAISHI, N. Wood and cellulosic chemistry. 2. ed. New York: Marcel Dekker, 2001. 914p. 
INANAGA, S.; OKASAKA, A.; TANAKA, S. Does silicon exist in association with organic compounds in rice plant? Japan Journal of Soil Science and Plant Nutrition, v.11, p.111-117, 1995.

JIN, S.; CHEN, H. Structural properties and enzymatic hydrolysis of rice straw. Process Biochemistry, v.41, p.1261-1264, 2006.

JONES, D.H. Phenylalanine ammonia-lyase: regulation of its induction, and its role in plant development. Phytochemistry, v.23, p.1349-1360, 1984.

KIM, S.G.; KIM, K.W.; PARK, E.W.; CHOI, D. Silicon-induced cell wall fortification of rice leaves: A possible cellular mechanism of enhanced host resistance to blast. Phytopathology, v.9, p.1095-1103, 2002.

KORNDÖRFER, G.H.; PEREIRA, H.S.; NOLLA, A. Análise de silício: solo, planta e fertilizante. Uberlândia: Universidade Federal de Uberlândia, 2004. 24p. (Boletim Técnico, 2)

KURODA, K.I.; SUZUKI, A.; KATO, M.; IMAI, K. Analysis of rice (Oryza sativa L.) lignin chromatography by pyrolysis-gas. Journal of Analytical and Applied Pyrolysis, v.34, p.1-2, 1995.

LAPIERRE, C. Application of new methods for the investigation of lignin structure. In: JUNG, H.G.; BUXTON, D.R.; HATFIELD, R.D.; RALPH, J. (Ed.). Forage Cell Wall Structure and Digestibility. Madison: American Society of Agronomy, 1993. p.133-166.

LEWIS, N.G.; YAMAMOTO, E. Lignin: occurrence, biogenesis and biodegradation. Annual Review of Plant Physiology and Plant Molecular Biology, v.41, p.455-496, 1990.

MA, J.F.; TAKAHASHI, E. Soil, fertilizer, and plant silicon research in Japan. Amsterdam: Elsevier, 2002. 325p.

MA, J.F.; TAMAI, K.; ICHII, M.; WU, G.F. A rice mutant defective in Si uptake. Plant Physiology, v.130, p.2111-2117, 2002.

MEIER, D.; FAIX, O. Pyrolysis-gas chromatography-mass spectrometry. In: LIN, S.Y.; DENCE, C.W. (Ed.). Methods in Lignin Chemistry. Berlin: Springer, 1992. p.313-321.

OU, S.H. Rice Diseases. 2.ed. Kew: Commonwealth Mycological Institute, 1985. 380p.

RALPH, J.; HATFIELD, R.D. Pyrolysis-GC-MS characterization of forage materials. Journal of Agriculture and Food Chemistry, v.39, p.1426-1437, 1991.

RIDE, J.P. Lignification in wounded wheat leaves in response to fungi and its possible role in resistance. Physiological Plant Pathology, v.5, p.125-134, 1975.
RODRIGUES, F.A.; DATNOFF, L.E.; KORNDÖRFER, G.H.; SEEBOLD, K.W.; RUSH, M.C. Effect of silicon and host resistance on sheath blight development in rice. Plant Disease, v.85, p.827-832, 2001.

RODRIGUES, F.A.; JURICK, W.M.; DATNOFF, L.E.; JONES, J.B.; ROLLINS, J.A. Silicon influences cytological and molecular events in compatible and incompatible rice-Magnaporthe grisea interactions. Physiological and Molecular Plant Pathology, v.66, p.144-159, 2005.

RUSH, M.C.; LEE, F.N. Sheath blight. In: WEBSTER, R.K.; GUNNELL, P.S. (Ed.). Compendium of Rice Diseases. St. Paul: American Phytopathological Society, 1992. p.22-23.

SARKANEN, K.V.; LUDWIG, C. Lignins: occurrence, formation, structure and reactions. New York: Wiley-Interscience, 1971. p.74-79.

SCALBERT, A.; MONTIES, B.; ROLANDO, C.; SIERRAESCUDERO, A. Formation of ether linkage between phenolic acids and gramineae lignin: a possible mechanism involving quinone-methide. Holzforschung, v.40, p.191-195, 1986.

SCHURT, D.A.; RODRIGUES, F; REIS, R.D.; MOREIRA, W.R.; SOUZA, N.F.A.; SILVA, W.A. Resistência física de bainhas de plantas de arroz supridas com silício e infectadas por Rhizoctonia solani. Tropical Plant Pathology, v.37, p.281-285, 2012.

SHANER, G.; FINNEY, R.E. The effect of nitrogen fertilization on the expression of slow-mildewing resistance in Knox wheat. Phytopathology, v.67, p.1051-1056, 1977.

SUN, R.C.; SUN, X.F.; WANG, S.Q.; ZHU, W.; WANG. X.Y. Ester and ether linkages between hydroxycinnamic acids and lignins from wheat, rice, rye, and barley straws, maize stems, and fast-growing poplar wood. Industrial Crops and Products, v.15, p.179-188, 2002.

SUMMERS, M.D.; JENKINS, B.M.; HYDE, P.R.; WILLIAMS, J.F; MUTTERS, R.G.; SCARDACCI, S.C. Biomass production and allocation in rice with implications for straw harvesting and utilization. Biomass and Bioenergy, v.24, p.163-173, 2003.

YOSHIDA, S.; OHNISHI, Y.; KITAGISHII, K. Chemical forms, mobility and deposition of silicon in rice plant. Soil Science and Plant Nutrition, v.8, p.15-21, 1962.

TSUTSUMI, Y.; KONDO, R.; SAKAI, K.; IMAMURA, H. The difference of reactivity between syringyl lignin and guaiacyl lignin in alkaline systems. Holzforschung, v.49, p.423-428, 1995.

WINSLOW, M.D. Silicon, disease resistance, and yield of rice genotypes under upland cultural conditions. Crop Science, v.32, p.1208-1213, 1992. 